NASA Technical Memorandum 87192

\title{
MMIC Antenna Technology Development in the 30/20 Gigahertz Band
}

(NASA-TM-87192) MMIC ANTENNA TECHNOLOGY DEVELOPMENT IN THE $30 / 20$ GIGAEERTZ BAND (NASA) 22 P HC AO2/MF AO 1 CSCL O9F

J. Smetana, T.J.Kascak, and R.E. Alexovich Lewis Research Center Cleveland, Ohio

Prepared for the



11th Annual Communications Satellite Systems Conference sponsored by the American Institute of Aeronautics and Astronautics San Diego, California, March 16-20, 1986 
J. Smetana, T.J. Kascak, and R.E. Alexovich

National Aeronautics and Space Administration

Lewis Research Center

Cleveland, Onio 44135

\section{Abstract}

Tnis paper presents a progress summary of NASA's efforts in developing 20 and $30 \mathrm{GHz}$ GaAs MMIC devices and an advanced satellite communications antenna system using these devices. In the interest of preserving resources such as frequency spectrum and orbital space the antenna system is being developed with multiple fixed spot beams and multiple scanning spot beams.

NASA set high goals for the MMIC development to push GaAs technology. These goals and the main features of the MMIC devices are discussed. Some packaging and characterization considerations are also discussed.

The $20 \mathrm{GHz}$ transmit antenna and $30 \mathrm{GHz}$ receive antenna are being developed separately. The approach selected is to perform contractual configuration studies, purchase a 20-GHz experimental antenna system (EAS) and perform in-house evaluation.

The features and key specifications of the EAS are discussed. Additional supporting technologies such as effects of coupling on modest sized arrays, MMIC matching techniques, in-house analytical capability, wideband and dual frequency microstrip patch array development, and MMIC packaging techniques are described.

Some plans for future work are also discussed.

\section{Introduction}

Fixed satellite service is a communications service between earth stations at highly populated areas using satellites to make the communications link between these stations. The fixed service includes communications for voice, video and data using trunking or private networks, and point to multipoint services such as distribution of television programming. In the United States, tnese domestic services are provided by U.S. commercial carriers using domestic satellites, referred to as DOMSAT'S. The frequencies used for this service are C-Dand, $6 \mathrm{GHz} / 4 \mathrm{GHz}$, and Ku-Dand $14 \mathrm{GHz} / 12 \mathrm{GHz}$ (uplink/downtink) respectively.

Studies conducted by NASA in the late $70^{\prime} \mathrm{s}$ have snown that the demand for orbital locations and frequency allocations for fixed satellite service, will exceed the orbit and spectrum capacity by the early 1990's. Even with reduced spacing of $2^{\circ}$, a new FCC spacing plan for fixed satellite service, the demand will likely exceed the capacity by 1990. To provide additional capacity the next allocated frequency band, $\mathrm{Ka}-\mathrm{b}$ and, $30 \mathrm{GHz} / 20 \mathrm{GHz}$, is being developed by INASA in the Advanced Communications Technology Satellite (ACTS) which is planned to be launched in 1989. The ACTS antenna systems will make use of multiple fixed and scanning spot beams.

Using multibeam antennas, coverage can be provided by a set of many narrow spot beams, fixed and scanning, as opposed to a single CONUS beam or a few zone beams provided by lower frequency $\mathrm{C}$ or Ku-band conventional satellite antennas. This permits extensive reuse of tne frequency bands and greatly increases the capacity of the orbital arc and spectrum. The generation of the multiple narrow beams, however requires beam forming components such as switches, phase shifters, power dividers, and fixed norns, all of which, when used with a single power source results in large system weights and power losses. The application of emerging technologies in monolitnic microwave integrated circuits (MMIC) in tne multiple beam antenna systems offers the potential for increased functional capability, reduced beam forming network weight, reduced losses, and increased reliability.

This report describes NASA's development of MMIC devices for transmitting antennas at $20 \mathrm{GHz}$, MMIC devices for receiving antennas at $30 \mathrm{GHz}$ and the utilization of these devices in transmitting and receiving experimental antenna systems.

\section{GaAs MMIC Technology Developments}

NASA Lewis Research Center has an on-going program to develop Monolithic Microwave Integrated Circuit (MMIC) devices in the 20 and $30 \mathrm{GHz}$ frequency bands and to develop multiple fixed and scanning beam phased-array antennas with a MMIC at each radiating element. The MMIC development includes two contracts for $20 \mathrm{GHz}$ transmit MMIC devices and two contracts for $30 \mathrm{GHz}$ receive MMIC devices. NASA is pursuing this MMIC development because of the potential advantages of MMICs at nign frequencies.

Figure 1 shows the block diagrams of the transmit portion of typical $20 \mathrm{GHz}$ scanning spot Deam satellite communications systems using (a) a TWT and (b) MIMIC devices. This illustration shows that even thougn the MMIC amplifier efficiency is considerably lower than the TWT, the MMIC system efficiency is competitive to that of the conventional TWT transponder. It also shows that the advanced antenna system is no longer the passive component that antenna designers have built in the past. The antenna systems now have gain, efficiency, isolation, reliability, and heat loss as design parameters. The advantages of the MMIC system will be discussed in terms of these parameters.

In order to acnieve optimum gain or isolation one needs to control the illumination of the reflector system. Given the variable phase and variable amplitude provided by the MMIC devices, using computer control, the illumination can be 
controlled dynamically. In satellite communications using several narrow spot beams at the same frequency it is important to maintain high isolation between beams. The dynamic control of phase and amplitude reduces interference by beam contour control as well as sidelobe level control.

Improved reliability is a fundamental result of circuit integration and using a large number of amplifiers in an antenna array. The circuit integration reduces the number of external connections (for a similar application) which are notoriously susceptible to failure. A large array of amplifiers provides reliability through graceful degradation.

Other MMIC advantages include small size, nigh speed switching, no external module tuning, reduced parasitics, and reduced uncertainities of KF parameters normally associated witn noninonolitnic circuits. Also the use of microelectronic fabrication metnods promises to offer the cost effective manufacture of the large quantities of MMICs, required for advanced phased array antenna systems.

The MMIL development concepts employ a microstrip design approach in which all the active and passive devices are fabricated on a gallium arsenide (GaAs) semiconductor substrate. An important feature of the MMICs is the large scale integration of many types of circuit elements onto a single cnip. The element types include field effect transistors (FETs, used both as switches and in amplifying circuits), capacitors, microstrip transmission lines, resistors, and diodes. Successful fabrication of MMICs at frequencies greater than $20 \mathrm{GHz}$ requires significant advances in various areas of GaAs technology. Major technology advances include submicron size definition, GaAs material development, processing compatibility for various types of devices, FET equivalent circuit modeling, microstrip design, and RF testing.

The potential advantages of MMIC devices make their application to phased array antennas attractive. Part of NASA's program includes the development and the demonstration of feasibility of using the devices developed on the MIMIC contracts in antenna arrays. The antenna development will be discussed later. Following are detailed descriptions of the MMIC development.

\section{$20 \mathrm{GHz}$ MMIC Development}

One of the $20 \mathrm{GHz}$ MillC developments is being conducted on NASA contract NAS 3-23247 with Rockwell International Corporation. The development includes two types of MMICs; a variable phase shifter (VPS), and a constant gain amplifier (CGA). The tecnnology goals for these devices are given in Table I. Photographs of the VPS and CGA are shown in Fig. 2.

The VPS is a five bit, switched differential line phase shifter, employing FET devices for switches. A two-stage buffer amplifier follows the phase shifters to compensate for the phase shifter losses. The MMIC also includes a circuit that regenerates the transmitted control bit and its complement to turn one switch on and the other off for better isolation. The VPS thus provides a digitally selectable phase snift capability of $0^{\circ}$ to $360^{\circ}$ in increments of $11.25^{\circ}$.

The CGA consists of a three-stage amplifier to provide the desired $200 \mathrm{~mW}$ output power. Each stage includes submicron FET devices with the appropriate bias network and matching networks. More detailed information on the VPS and CGA development nave been reported by Rockwell.1

Texas Instruments of Dallas, Texas on NASA contract NAS 3-22886 is developing a $20 \mathrm{GHz}$ variable power amplifier (VPA) that is to be used to provide the power level control function in a phased array antenna feed. The technology goals for the VPA are given in Table I and a photograph is shown in Fig. 3 .

Tne objective of the VPA development is to provide an amplifier that is electronically switchable to any one of five output power levels: $500,125,50,12.5$, and $0 \mathrm{~mW}$. The efficiency varies from 15 percent at the $500 \mathrm{~mW}$ level to 6 percent at the $12.5 \mathrm{~mW}$ level. The VPA consists of a four-stage dual gate FET amplifier and a D/A converter on a 3.05 by $6.45 \mathrm{~mm} \mathrm{GaAs}$ chip. The D/A converter provides the required bias voltage to the second gate of a dual gate FET in each stage for control of the output power level. Power control with a dual gate FET has several advantages. The FET gain can be changed over a large dynamic range (20 to $40 \mathrm{~dB}$ ). Over a large portion of this range, the transmission phase snift is less than $5^{\circ}$ and the FET input/output impedances are essentially constant providing a nearly constant shape of the gain-frequency response curve. Texas Instruments has reported on the VPA development at the IEEE 1985 Monolithic Circuits Symposium.?

\section{$30 \mathrm{GHz}$ MMIC Development}

Two parallel efforts to develop a $30-\mathrm{GHz}$ receiver are in progress under NASA contracts NAS 3-23357 with Hughes, Torrance Research Center, and NAS 3-23356 with Honeywe 11 Corporate Technology Center in Bloomington, Minnesota. The technology goals given in Table 1 are the same for both contracts. Five separate receiver submoaules are to be developed; a low noise amplifier, a variable amplifier with external control, a variable phase snifter with external controls, a mixer, and an IF amplifier.

With only one half of the program completed, a number of advances in the $30 \mathrm{GHz}$ MMIC technology have been accomplished. Hughes has fabricated a two-stage low noise amplifier with $13 \mathrm{~dB}$ gain and $6.5 \mathrm{~dB}$ noise figure (goals were $12 \mathrm{~dB}$ gain with $4.5 \mathrm{~dB}$ noise figure). Hughes has also fabricated the IF amplifier. Honeywell has made an important advance in the gain control amplifier development with the fabrication of a $30 \mathrm{GHz}$ dual-gate 0.25 micron FET. Preliminary test results show the device gain to be approximately $10 \mathrm{~dB}$. By varying the second gate bias, the range in power level adjustment is $25 \mathrm{~dB}$.

Altnough they responded to the same NASA goals, Honeywe 11 and Hughes have taken different approacnes in their design concepts, as shown in Fig. 4. The Honeywell approach has a $30 \mathrm{GHz}$ phase shifter and variable gain control. The 
phase snifter uses a switching network (employing FET devices as switches to divert RF signals between two differential line lengths for three Dits $\left(45^{\circ}, 90^{\circ}\right.$, and $\left.180^{\circ}\right)$. An analog loaded line is tapped and calibrated at tne three lower levels $\left(11.25^{\circ}, 22.5^{\circ}\right.$, and $\left.33.75^{\circ}\right)$ to provide the more difficult two bits. The Hughes approach utilize: a Lange coupler and a pair of GaAs Schottky diodes to form an analog phase shifter circuit, which operates at the local oscillator frequency $(23.5$ to $26 \mathrm{GHz})$. The Hugnes variable gain amplifier is at IF.

The MMIC Developinent goals were intentionally set nign to advance the state-of-tne-art of GaAs tecnnology. The $30 \mathrm{GHz}$ developinent is more ambitious tnan the $20 \mathrm{GHz}$ since it is intended eventually to combine the five receiver functions on a single chip. The overall progress is encouraging, considering the ambitious program objectives. MMIC devices from these contracts will be made available for incorporation into the antenna technology development efforts, but more work is needed to provide reproduciole characteristics.

\section{Antenna Tecnnology Development}

The objectives of this part of the program are to develop an MMIC antenna system that stresses technology extendable to other frequency Dands, facilitates frequency reuse and increases the orvital utilization. To accomplish these objectives NASA plans to develop the technology for nign gain multiple beam antenna systems that use MMIC devices at each radiating element of an array feed. 3 The purpose of this development effort is not to build a flight model, but to demonstrate tne feasioility of using MMICs in array feeas and to develop a data base.

The approach chosen by NASA was to investigate separately a $20 \mathrm{GHz}$ phased array-fed dualreflector transinit antenna and a $30 \mathrm{GHz}$ phased array-fed dual-reflector receive antenna. A multiyear program is in progress whicn began with contractual configuration studies to develop a data base of relevant configurations and to develop detailed design concepts. Investigative studies of the $20 \mathrm{GHz}$ transmit system were performed by COMSAT Laboratories, ${ }^{4}$ Contract NAS 3-23250, and Harris Corporation, ${ }^{5}$ Contract NAS 3-23252. Investigative studies of the $30 \mathrm{GHz}$ receive system were performed by General Electric Company, Electronics Laboratories, ${ }^{6}$ on NASA contract NAS 3-23780 about a year after the 20 $\mathrm{GHz}$ studies began.

\section{Antenna Configurations}

The investigations under the configuration studies contracts were limited to dual reflector systems. Two optical configurations of dual offset reflector systems shown in Fig. 6 can be used for beam steering given the choice of variable phase shift or variable power amplitude functions. In a confocal paraboloidal configuration, Fig. 6(a) (a nonfocused optical system with the subreflector in the near field), beam steering is accomplished by tilting the phase front. This configuration is favorable to rapid electronic steering such as a scanning spot beam antenna. In a focused optical system using a parabolic main reflector and nyperbolic subreflector, as in Fig. 6(b), beam pointing is achieved by scanning the phase center of a cluster of elements across the focal surface. This configuration is most favorable for use in a fixed spot beam application. However, if one were to design a $30 / 20 \mathrm{GHz}$ antenna system (not in NASA's plans) one would require a data base for fixed or scanning beams using both focused and unfocused configurations.

When a large number of beams and/or a high EIKP are required some trade-offs become necessary. A nign EIRP requires a large array of radiating elements and a multiplicity of beams must share the same aperture space. They share tne space eitner by interleaving the elements or each array occupies a smaller part of the available aperture space. Botn lead to reduced aperture efficiency. An alternate approach is to use a linear combining of several Deams so that each beam uses the same array of elements as shown in Fig. 7. In this configuration the loss, (10 log $n$ (in $d B$ ) for $n$ combinations) through the combiner (for noncoherent signals) can be compensated with additional amplification.

The configuration studies resulted in eight transmit and two receive configurations featuring multiple scanning spot beams and multiple fixed spot beams. The configurations include focused and unfocused optics as well as Gregorian and Cassegrain dual reflector systems.

Test and Evaluation

NASA plans for test and evaluation include (1) the characterization of all types of MMIC devices, (2) the fabrication, test and evaluation of small subarrays which will demonstrate the effectiveness of the individual functions such as variable phase snift or variable gain and (3) the design and fabrication of an experimental antenna system (EAS) which will be used to demonstrate and evaluate most of the antenna configurations developed in the studies.

At the time of this report NASA had received only one delivery of MMIC chips. They were the $30 \mathrm{GHz}$ phase shifter portion of the Honeywell receiver MMIC. One hundred devices were delivered. All of the 20 and $30 \mathrm{GHz}$ devices are to be characterized on an automatic network analyzer measuring phase shift, insertion loss gain and phase dispersion. Figure 8 is a typical $30 \mathrm{GHz}$ variable phase shifter characterization.

These devices were then installed in two types of antenna subarrays to demonstrate that predictable electronic steering can be achieved. One type was a tapered circular horn subarray shown in Fig. 9(a) demonstrating the use of MMIC devices in a waveguide housing shown in Fig. 9(b). The other was a microstrip patch array Fig. 10(a) witn tne chips mounted on the other side on a microstrip board which included a corporate divider and control lines for the chips, Fig. 10(b). Figure 11 shows the calculated pointing and the measured results for the tapered horn cluster. The microstrip array is in process of testing.

The design and fabrication of the EAS is on-going under NASA contract NAS 3-23789 with General Electric Company, Valley Forge Space 
Center. While the EAS is intended to demonstrate the configurations developed on NASA study contracts, it is expected to become a general laboratory instrument to perform other 20 to $60 \mathrm{GHz}$ experiments. Figure 12 shows the EAS erected in three reconfigurable optical assemblies (a) the Gregorian confocal paraboloid, (b) the Cassegrain confocal paraboloid and (c) the traditional Cassegrain with a hyperboloid subreflector. The subreflectors tolerances are within $0.10 \mathrm{~mm}$, rms, and $0.25 \mathrm{~mm}$, peak, deviation from the true curve. The main reflector, designed and fabricated at NASA is expected to be witnin $0.02 \mathrm{~mm}$, rms, and $0.05 \mathrm{~mm}$, peak deviation from the true paraboloid. Tnese tolerances can allow measurement of the feed systems with negligible contribution to errors from the optical portion of the system. It also can permit future work to be performed up to $60 \mathrm{GHz}$ or more Fig. 13 shows the overall design concept of the EAS.

The $20 \mathrm{GHz}$ transmit MMICs (VPS, CGA, and VPA) are to be used in the EAS. To incorporate these MMICs in a phased array system, the MMIC chip must be interconnected to the control computer. In NASA's EAS this is accomplished using the MMIC holder shown in Fig. 14. The design of this holder addresses the physical protection of the MMIC chip, the electrical interconnectivity requirements, and the chip thermal dissipation requirements. The chip is to be bonded to the nolder with a eutectic solder, one that provides a good electrical ground plane connection to the cnip, and a low thermal resistance path for heat rejection. Another important consideration in Donding tne MMIC chip is minimizing the thermal expansion stress between the chip and the holder. The electrical interconnections between the chip and the nolder are of two basic types; (a) $20 \mathrm{GHz}$ $\mathrm{RF}$ and (D) control and bias lines. The RF input and output lines will be the most critical being sensitive to propagation mismatch, resistive loss, contact losses and step discontinuities. These will be discussed in more detail later.

MMIC holders are mounted in waveguide housings similar to one shown in Fig. 15. For the 20 $\mathrm{GHz}$ transmit configurations the three functional types of MMIC (the VPS, VPA, and CGA) are mounted in separate housings. These housings in conjunction with horns, waveguide dividers, flexible waveguide, and other components can be assembled into a variety of feed system configurations. Figure 7 is a typical configuration used with unfocused optics, as for example the confocal paraboloid, to generate an electronically scanned beam. The EAS is a descoped version of this configuration having only two simultaneously generated beams, using 48 horns in this configuration which can be either co-polarized or orthogonally polarized. This configuration is particularly interesting in that it can simulate either a scanning spot beam or fixed spot beam. In addition, it can simulate both scanning and fixed spot beams witn the focused optics by selectively turning-on MMIC functions for seven horn clusters at a time using computer control.

One of the important demonstrations tnat is plannea is the simulation of three fixed spot Deains to Wasnington, New York, and Boston, A three by five array of elements will be used for the simulation with a three by three array for each Deam. Each Deam shares horns with the otner two and an ortnomode transducer linearly polarizes the New York Deam ortnogonally to the Boston and Washington beams. A nign degree of isolation Detween these beams (at the same frequency) is possible due to a combination of polarization isolation, low sidelobe level and contouring. All of these are enhanced with dynamic phase and amplitude weignting made possible with the computer controlled variable phase and variable amplitude functions in the MIMIC devices.

A $30 \mathrm{GHz}$ receive experimental antenna feed system (EAFS) which physically replaces the $20 \mathrm{GHz}$ feed will simulate the configurations illustrated in Fig. 16. These configurations are the ones developed by GE, Electronics Laboratory, in their study contract. Nineteen element clusters receive signals from one incoming beam. The GE studies snowed tnat in a space application an array of 578 elements will make available a multiplicity of scanning beam positions as shown in Fig. 17(a). Six scanning beams are produced by turning on a $1 y$ element cluster in each sector and then, switching from one cluster to another. Eighteen fixed spot Deams are produced by turning-on clusters which are associated witn forming beams froin the positions shown in Fig. 17(b). The EAFS is scaled aown by decreasing the required number of radiating elements and MMIC devices. The minimum required to effectively demonstrate tne receive configurations is left to the discretion of the offerors. GE determined in their studies that the unfocused approach was not practical for a receive system.

\section{Supporting Tecnnology}

Investigations still in progress are being performed to support array systems design. One of these is a study performed on NASA Grant NAG 3-291 with Case Western Reserve University by Dr. Robert E. Collin. The objective of this effort is to develop accurate calculation of coupling effects in finite sized array antennas. Models of arrays of open-ended rectangular and circular waveguides and arrays of rectangular and circular horns with a ground plane at the aperture of each of these arrays were analyzed.7

Another supporting technology involves two aspects of the interconnectivity of a MMIC investigated on NASA Cooperative Agreement NCC 3-38 with University of Illinois by Dr. Raj Mittra. The MMIC naving been fabricated with litnograpnic techniques can be assumed to have reproducible RF characteristics. In order to preserve these characteristics it is important at frequencies greater tnan $20 \mathrm{GHz}$ to accurately matcn the MMIC device to its external circuitry. The MMIC cnip mounted on another substrate generally has a step discontinuity in impedance at its RF input and output terminals. ${ }^{8}$ There are step changes in three parameters (1) line width (2) substrate tnickness, and (3) dielectric constant. If one can determine the S-parameters of each of these abrupt discontinuities, then it should be possible to cascade them together in a manner which will yield a low loss transition. A mode matching method at the plane of the discontinuity is being used to develop a computer analysis which will determine the S-parameters and solve for the best matching network 9,10 . 
Several in-house supportiny activities were performed or are in progress. A computer analysis capability was developed which can accurately predict the performance of all types of arrays and reflector systems. Several approaches such as geometrical tneory of diffraction, super position and mutual coupling calculations 11,12 were used to provide a complete and accurate capability. Investigative efforts are underway to develop widedand (13 percent BW) microstrip patch arrays and dual frequency (20 and $30 \mathrm{GHz}$ ) microstrip patches. Microstrip corporate divider design efforts are also underway to provide lower loss and better isolation between outputs. A continuous effort is underway investigating MMIC packaging techniques.

\section{Future work}

One of the most important advantages of using MMIC devices for satellite antennas is the small size of the MMIC and the potential for reducing the weignt and cost of the satellite antenna. Our current efforts (reported herein) have utilized the waveguide housings and horns to demonstrate the feasibility of IMIIC antenna systems. Future systems will take advantage of the small size, light weight and easily produced microstrip patch arrays, and inicrostrip networks.

Anotner important advantage is the potential for dynamic control of MMIC arrays. Future improvements in isolation will be investigated through the use of better resolution or more steps (as many as 10) in amplitude control. Phase and amplitude control are expected to be used for correction of aberation as for example those caused by thermally distorted (in space) reflectors. The use of fibre optics, to reduce the complexity of MMIC control and interconnectivity will be investigated.

Several aspects of integrating the MMIC array antenna into a spacecraft communications system will also be investigated. For example, the dimensional and thermal control requirements due to the high heat dissipation from MMIC arrays will be analytically and experimentally investigated. Methods will be developed for conducting the waste neat to remote space facing radiators.

\section{Concluding Remarks}

This paper has presented a progress summary of NASA's efforts in developing 20 and $30 \mathrm{GHz}$ GaAs MMIC devices and an advanced satellite communications antenna system using these devices. In the interest of preserving resources such as frequency spectrum and orbital space the antenna systern is being developed with multiple fixed spot beams and multiple scanning spot beams.

NASA set nigh goals for the MMIC development to pusn GaAs technology. These goals and the main features of the MMIC devices were discussed. Some packaging and characterization considerations were also discussed.
The $20 \mathrm{GHz}$ transmit antenna and $30 \mathrm{GHz}$ receive antenna are Deing developed separately. Tne approacn selected is to perform contractual configuration studies, purchase a $20 \mathrm{GHz}$ experimental antenna system (EAS) and perform in-nouse evaluation.

The features and key specifications of the EAS were discussed. Additional supporting technologies sucn as effects of coupling on modest sized arrays, MMIC matching techniques, in-house analytical capability, wideband and dual frequency microstrip patch array development and MMIC packaging techniques are described.

Some plans for future work were also discussed.

\section{References}

1. Gupta, A., Kaelin, G.; Stein, R., Huston, S., Ip, K., Petersen, W., Mikasa, M., and Petroff, I.; "A $20 \mathrm{GHz} 5$-Bit Phase Snift Transmit Module with io dB Gain," in 1984 GaAs IC Symposium Technical Digest, IEEE, New York, 1984, pp. 197-200.

2. Saunier, P., Tserng, H. Q., Kim, B., and Westpna1, G. H., "Monolitnic GaAs Dual-Gate FET Variable Power Amplifier Module," Proceedings 1985 IEEE Microwave and Millimeter Wave Monotithic Circuits Symposium, edited by M. Conn, IEEE, New York, 1985, pp. 1-3.

3. Smetana, J., "Application of MMIC Modules in Future Multiple Beam Satellite Antenna Systems," NASA TM-83344, 1982.

4. Sorbel10, R.M., Zaghloul, A.I, Lee, B.S., Sidaigi, So, and Geller, B.D., "Phased ArrayFed Antenna Configuration Study," NASA CR-168232, 1983.

5. Crosswell, W.F., Ball, D.E., and Taylor, R.C., "Phased Array-Fed Antenna Configuration Study" NASA CR-168077, 1983.

6. Nester, W.H., Cleaveland, B., Edward, B., Gotkis, S., Hesserbacker, G., Loh, J., and Mitche11, B., "Configuration Study for a 30 $\mathrm{GHz}$ Monolithic Receive Array," NASA CR-174697, 1 y84.

7. Silvestro, J., "ivutual Coupling in Finite Arrays of Rectangular Apertures, "Master's Tnesis, Case Western Reserve University, May 1984 .

8. Smetana, J., Farr, E., and Mittra, R., "Characterization of MMIC Devices for Active Array Antennas," NASA TM-86907, 1984.

9. Farr, E., "Application of Mode Matching Techniques to Printed Circuit Discontinuities," Doctoral Thesis, University of Illinois, 1985.

10. Feldman, U., "Characterization of Microstrip Discontinuities in the Time and Frequency Domains," Master's Thesis, University of Illinois, June 1985 . 
11. Lam, P.T.C.; Lee, S.W., and Acosta, R., "Secondary Pattern Computation of an Arbitrary Shaped Main Reflector," NASA TM-8716', 1985.
12. Acosta, R.; "Computation of the Characteristics of a Generalize Antenna," NASA TM-87185, 1985.

TABLE I. - MMIC PERFORMANCE GOALS

\begin{tabular}{|c|c|}
\hline Design parameter & Performance goals \\
\hline \multicolumn{2}{|c|}{ Variable phase shifter } \\
\hline $\begin{array}{l}\text { RF band, GHz } \\
\text { Gain, dB } \\
\text { Phase bits, deg } \\
\text { Phase control } \\
\text { Mechanical design } \\
\text { Cnip size, mm }\end{array}$ & $\begin{array}{r}17.7 \text { to } 20.2 \\
0 \\
11.25,22.5,45,90, \text { and } 180 \\
\text { Five bit digital input } \\
\text { Monolithic } \\
4.7 \text { by } 4.7\end{array}$ \\
\hline \multicolumn{2}{|c|}{ Constant gain amplifier } \\
\hline $\begin{array}{l}\text { RF band, GHz } \\
\text { RF power out, mW } \\
\text { Gain, dB } \\
\text { Efficiency, percent } \\
\text { Mechanical design } \\
\text { Cnip size, mm }\end{array}$ & $\begin{array}{r}17.7 \text { to } 20.2 \\
200 \\
16 \\
15 \\
\text { Monolithic } \\
3.1 \text { by } 1.5\end{array}$ \\
\hline \multicolumn{2}{|c|}{ Variable power amplifier } \\
\hline $\begin{array}{l}\text { RF band, GHz } \\
\text { RF power out, W } \\
\text { Gain, dB } \\
\text { Efficiency, percent } \\
\text { Amplitude control } \\
\text { Mechanical design } \\
\text { Chip size, mm }\end{array}$ & $\begin{array}{r}17.7 \text { to } 20.2 \\
0 \text { to } 0.5, \text { variable } \\
20 \text { max., variable } \\
15 / 6 \\
\text { Four bit diginal input } \\
\text { Monolithic } \\
3.05 \text { by } 6.45\end{array}$ \\
\hline \multicolumn{2}{|c|}{$30 \mathrm{GHz}$ receiver } \\
\hline $\begin{array}{l}\text { RF band, GHz } \\
\text { If center frequency, GHz } \\
\text { Noise figure at room } \\
\text { temperature, dB } \\
\text { RF/if gain, dB } \\
\text { Gain control, dB } \\
\text { Module power consumption, } \mathrm{mW} \\
\text { Phase and gain control } \\
\text { Mechanical design } \\
\text { Chip size, mm }\end{array}$ & $\begin{array}{r}27.5 \text { to } 30 \\
\text { Between } 4 \text { to } 8 \\
\text { At least six levels; } 30,27, \\
24,20,17 \text { and off } \\
\text { at highest level of } \\
250 \text { in all states except } \\
\text { off. In off state, } 25 \\
5 \text { and } 4 \text { bit digital input } \\
\text { Monolithic } \\
12 \text { by } 7\end{array}$ \\
\hline
\end{tabular}



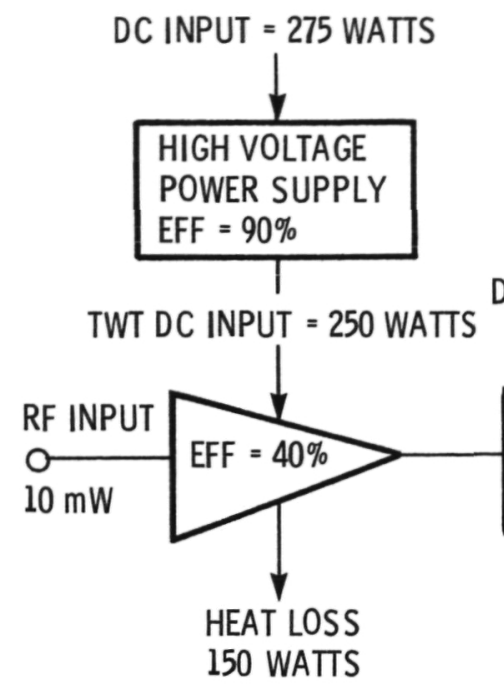

DC INPUT = 15 WATTS



(a) TWT system.

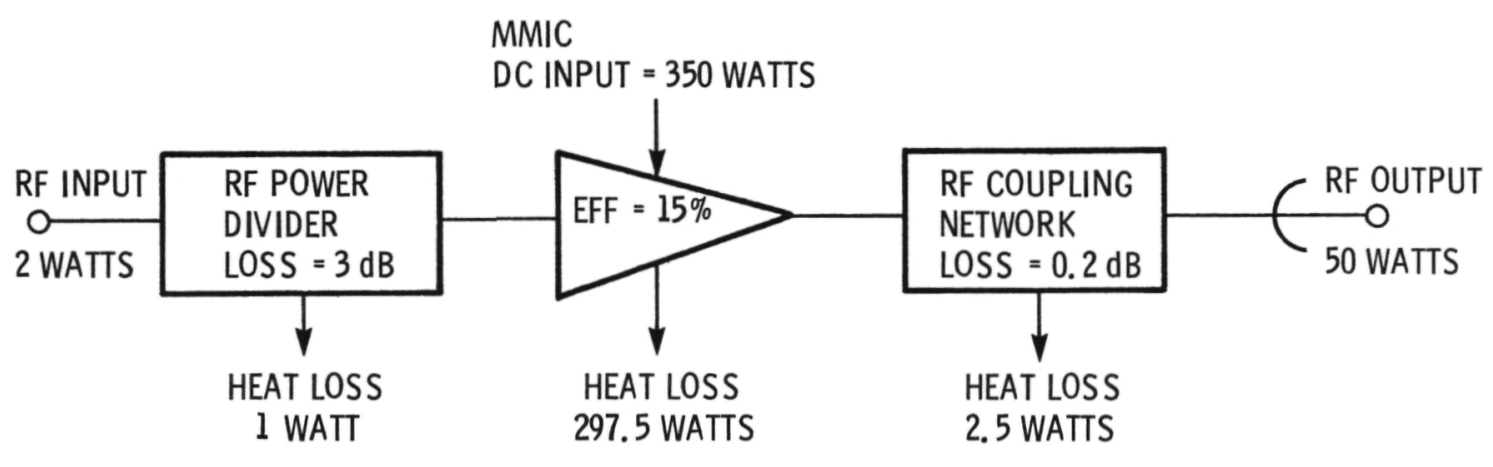

(b) MMIC system.

Figure 1. - Comparison between tradition TWT and MMIC scanning beam array antenna systems. 


\section{$\cos 10$ OF FOOR QUALTY}

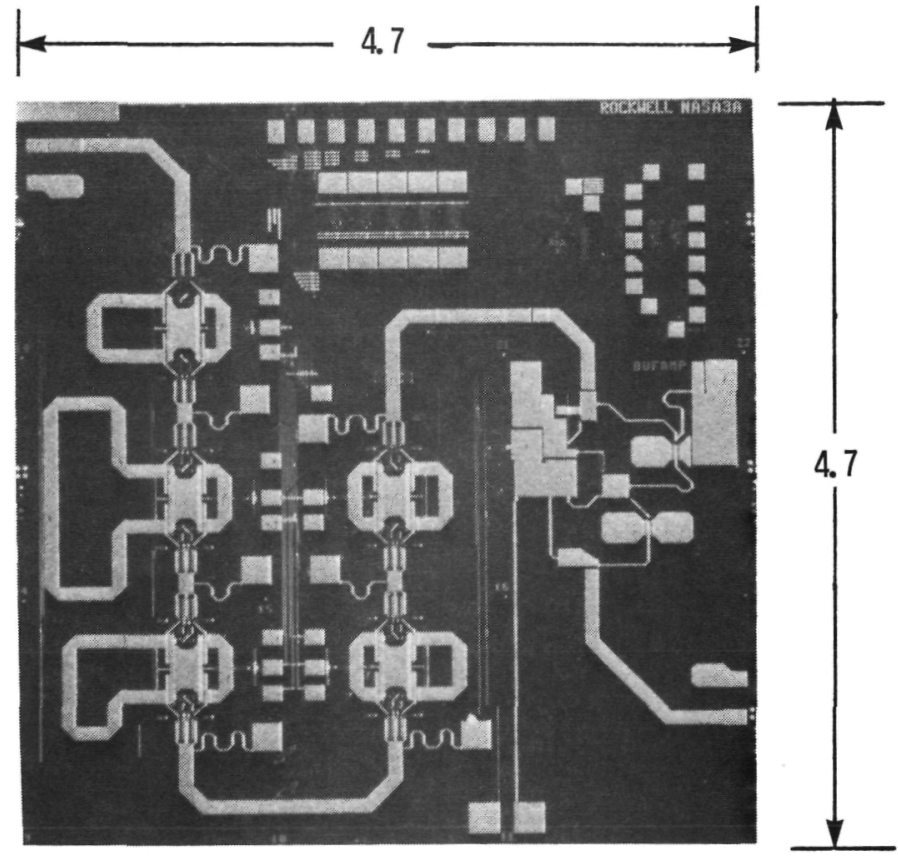

(a) $20 \mathrm{GHz} \mathrm{S}$-bit variable phase shift.

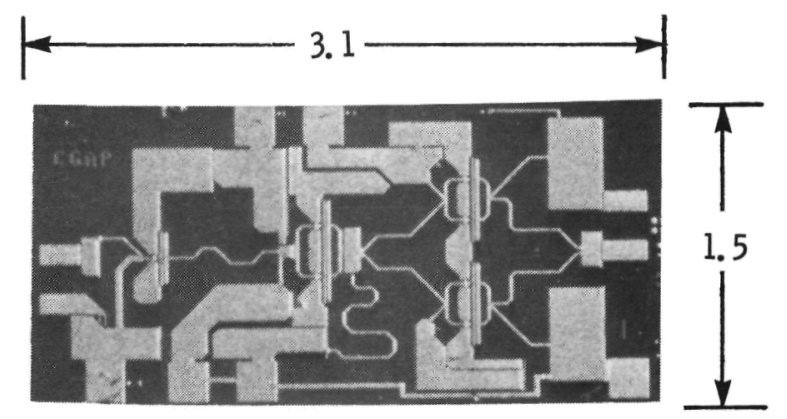

(b) Constant gain amplifier.

Figure 2. - २० GHz MMIC devices developed by Rockwell International.

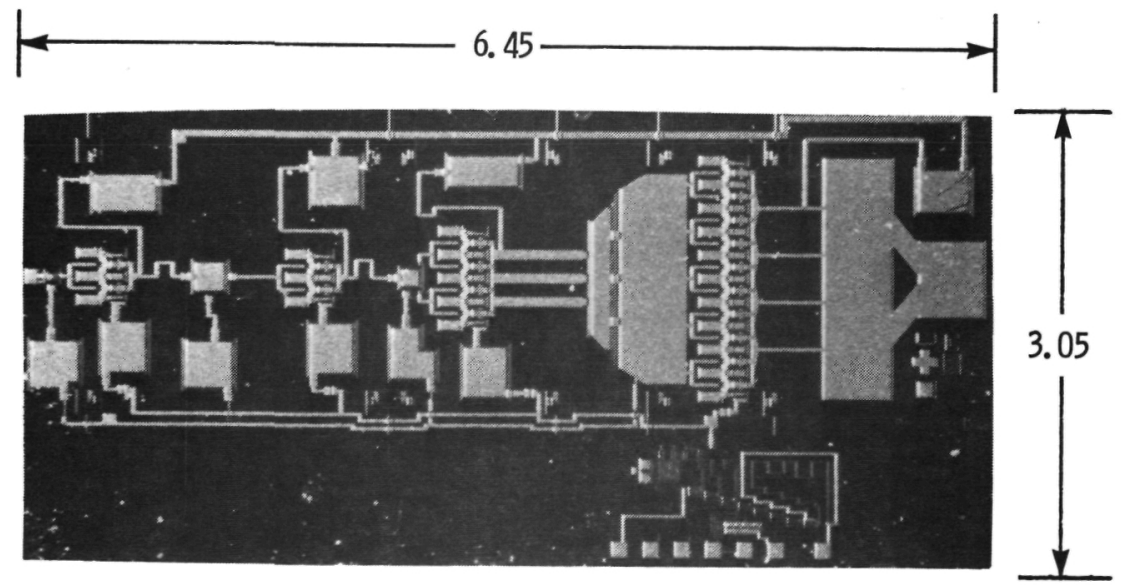

Figure 3, - Variable power amplifier MMIC developed by Texas Instruments. 




(a) Honeywell approach.

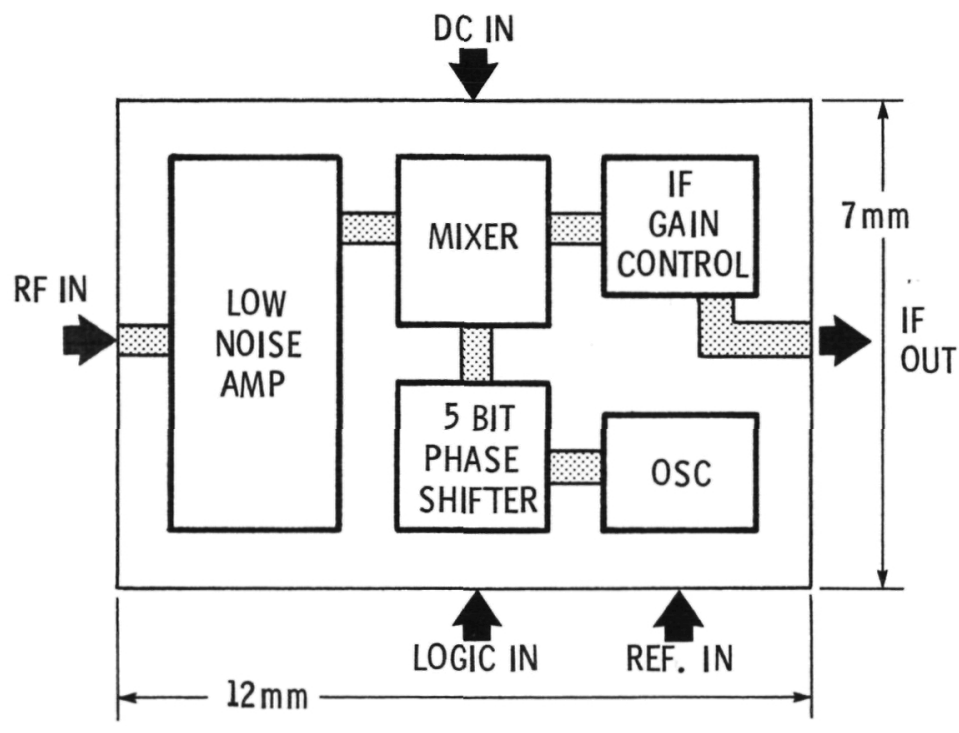

(b) Hughes approach.

Figure 4. - Block diagrams of the fully integrated $30 \mathrm{GHz}$ receive MMIC concepts. 


\section{Ohroth she is \\ OF POOR QUALITY}

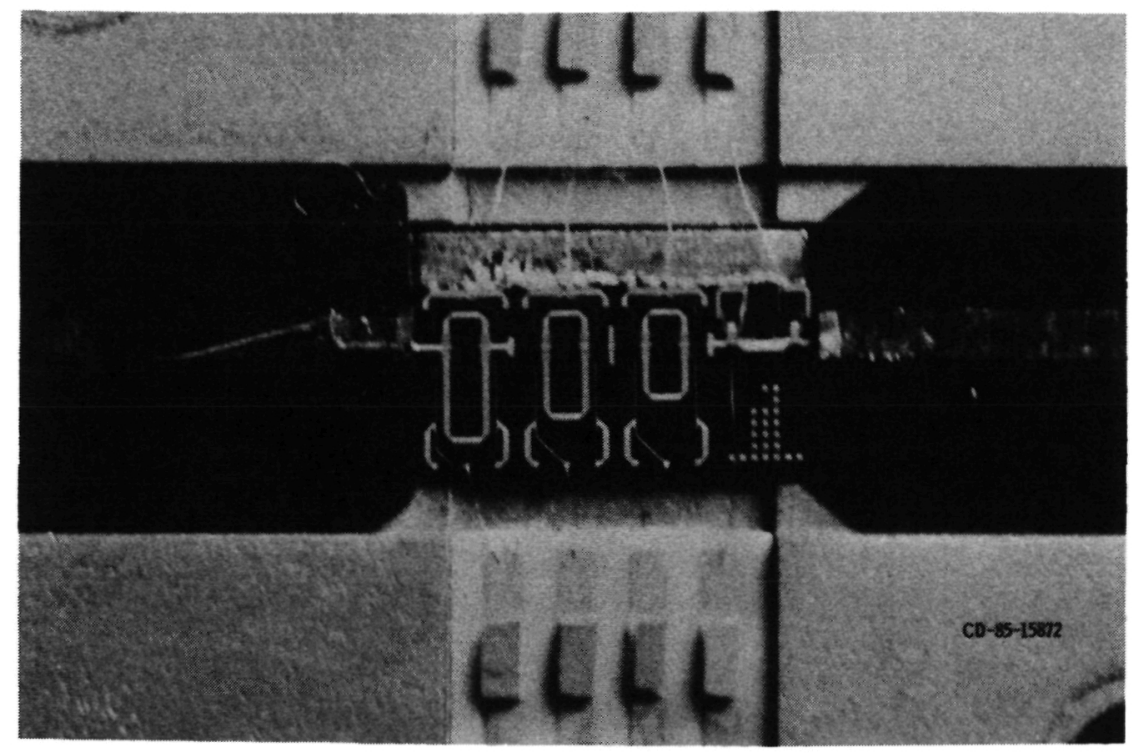

Figure 5. - $30 \mathrm{GHz}$ variable phase shift MMIC submodule developed by Honeywell.

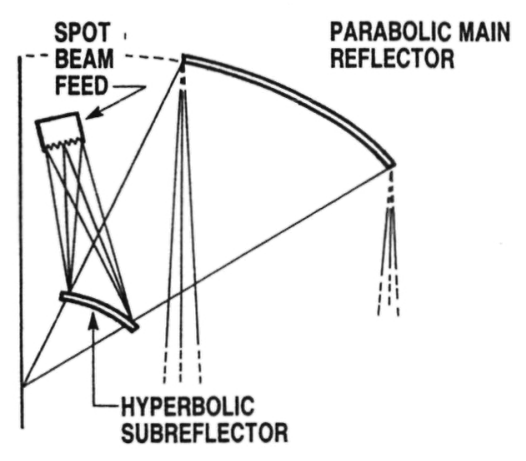

TRADITIONAL CASSEGRAIN

(FOCUSED)

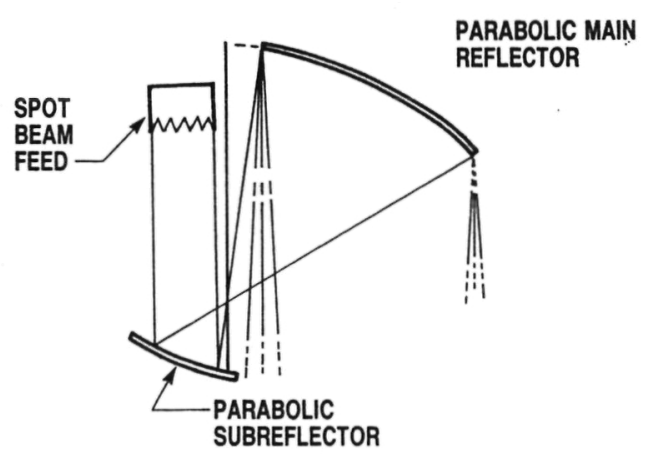

GREGORIAN CONFOCAL PARABOLOID (UNFOCUSED)

Figure 6. - Typical reflector configurations. 


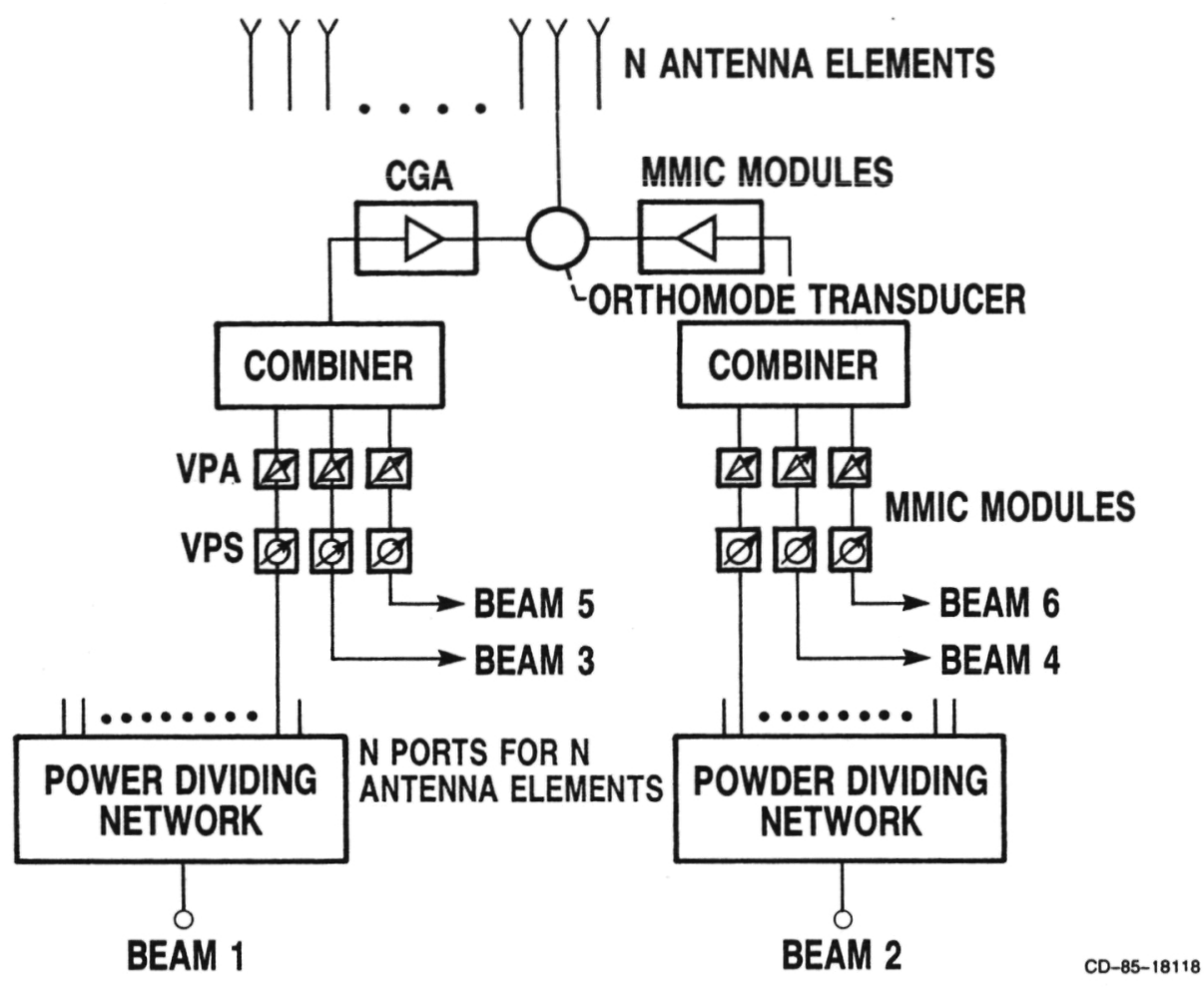

Figure 7. - Typical transmit configuration. 




(a) MivilC insertion loss measurement.

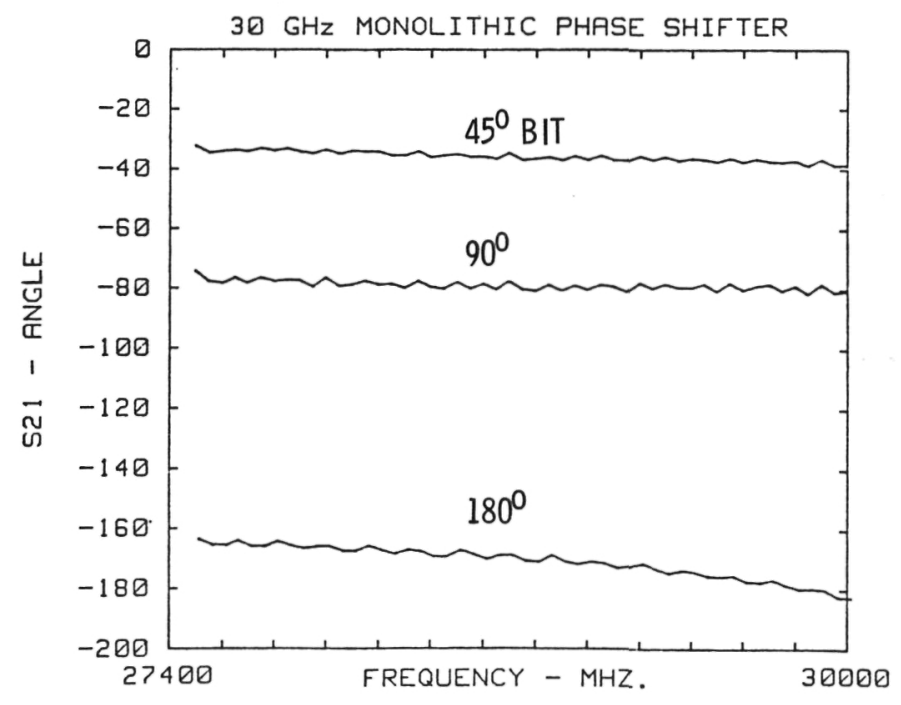

(b) MMIC phase shift measurement.

Figure 8. - Typical MMIC characterization. 


\section{ORIGINAL PSER IS \\ OF POOR QUALITY}

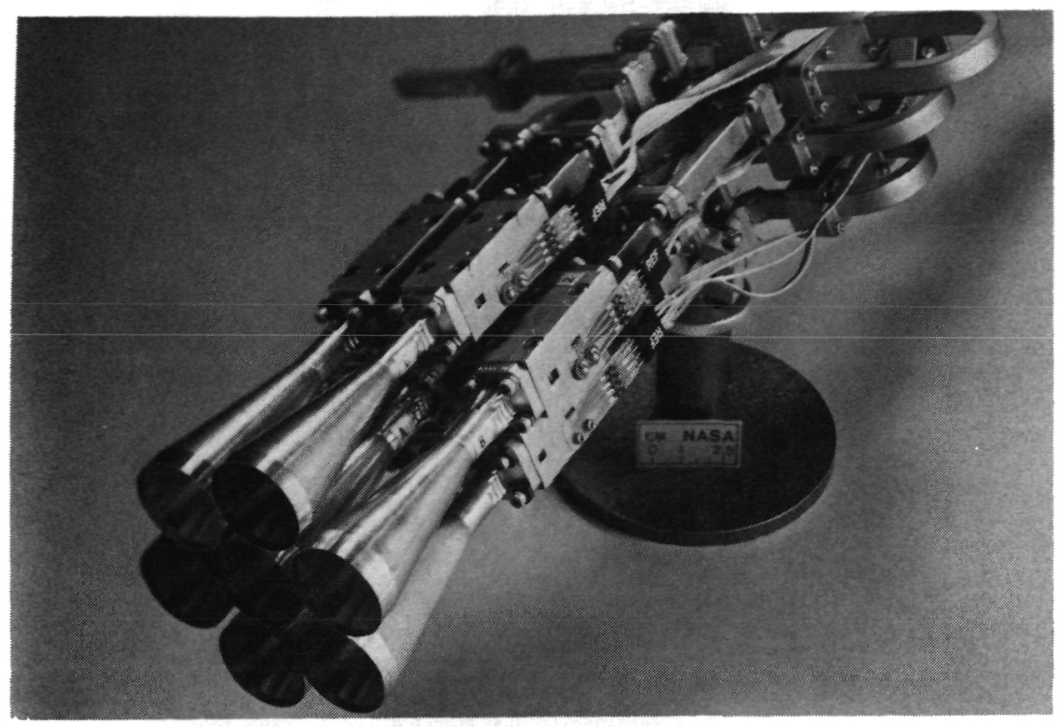

(a) Seven horn subarray.

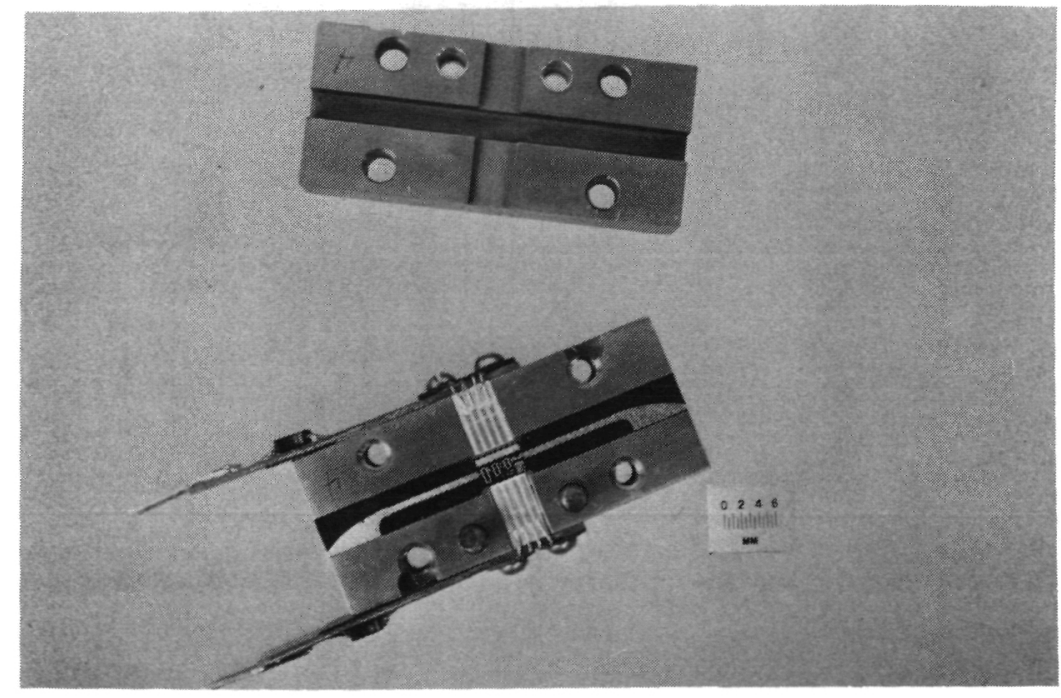

(b) $30 \mathrm{GHz}$ MMIC in waveguide housing.

Figure 9. - $30 \mathrm{GHz}$ MMIC pointing demonstration with horn array. 


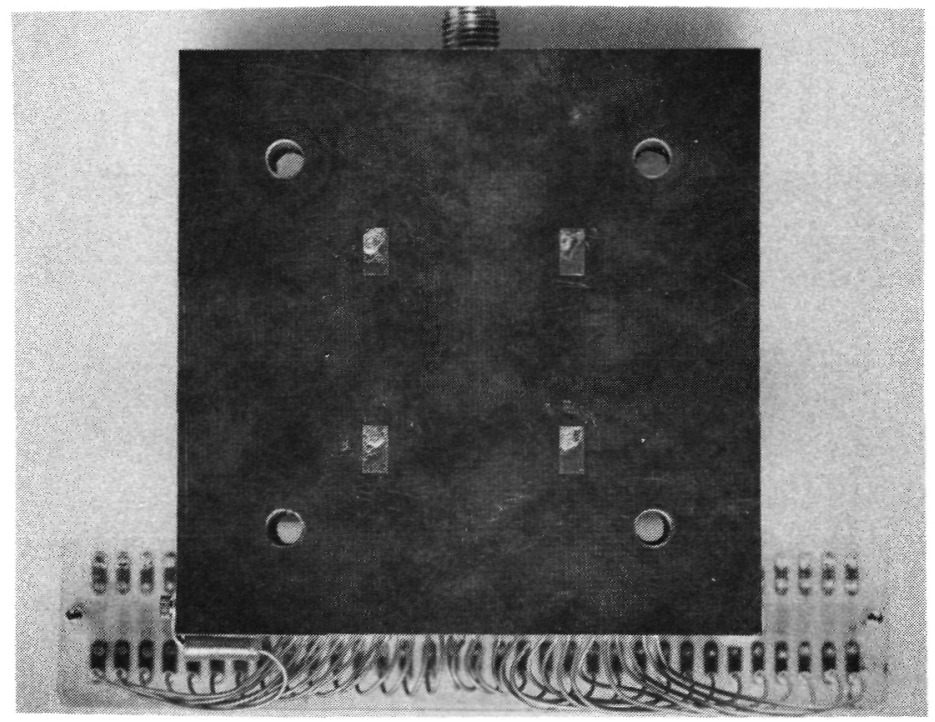

(a) $30 \mathrm{GHz}$ microstrip subarray.



(b) $30 \mathrm{GHz}$ MMIC interconnectivity.

Figure 10. - $30 \mathrm{GHz}$ MMIC pointing demonstration with microstrip array. 


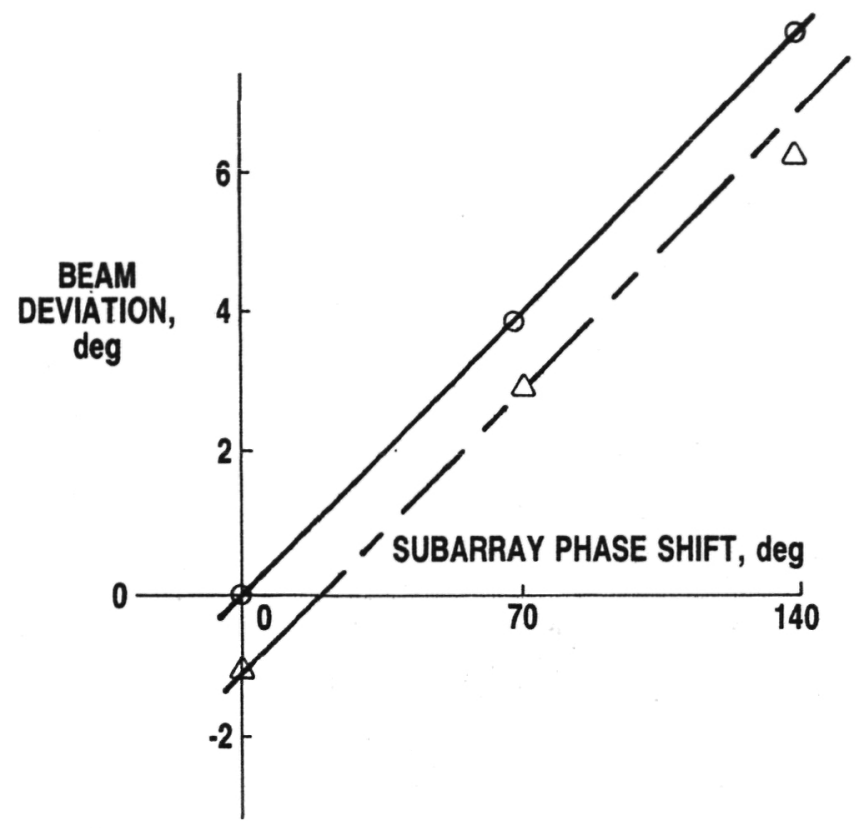

CD-85-18137

Figure 11. - Seven horn beam deviation. 


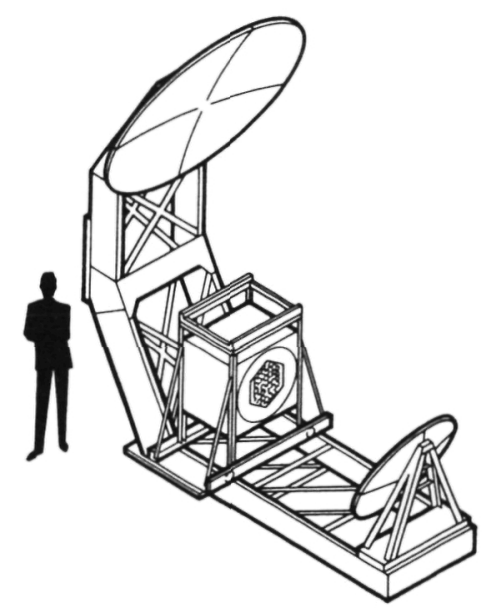

(a) Gregorian confocal paraboloid.

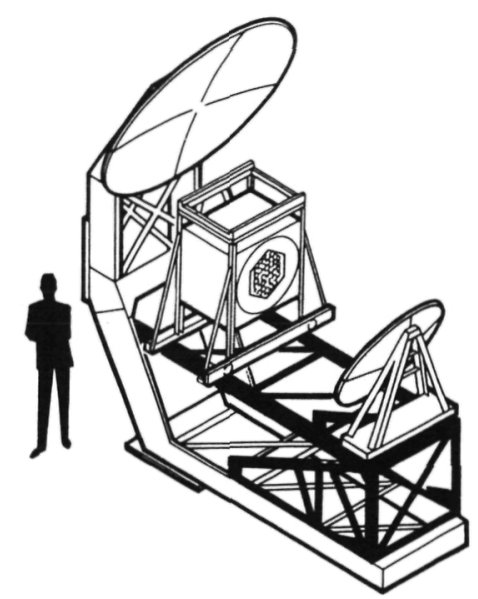

(b) Cassegrain confocal paraboloid.

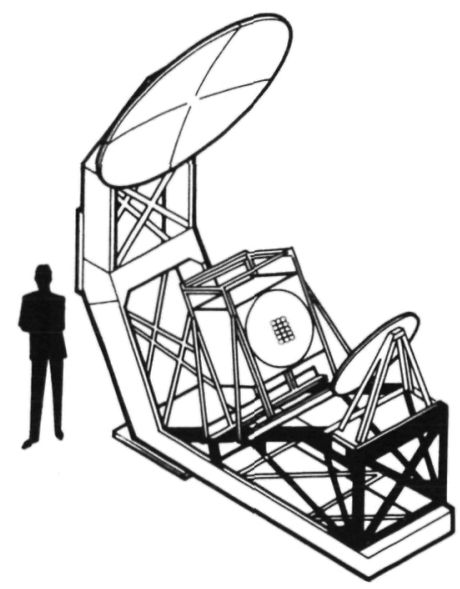

(c) Conventional Cassegrain with a hyperbolic subreflector.

Figure 12. - The experimental antena system optics configurations. 

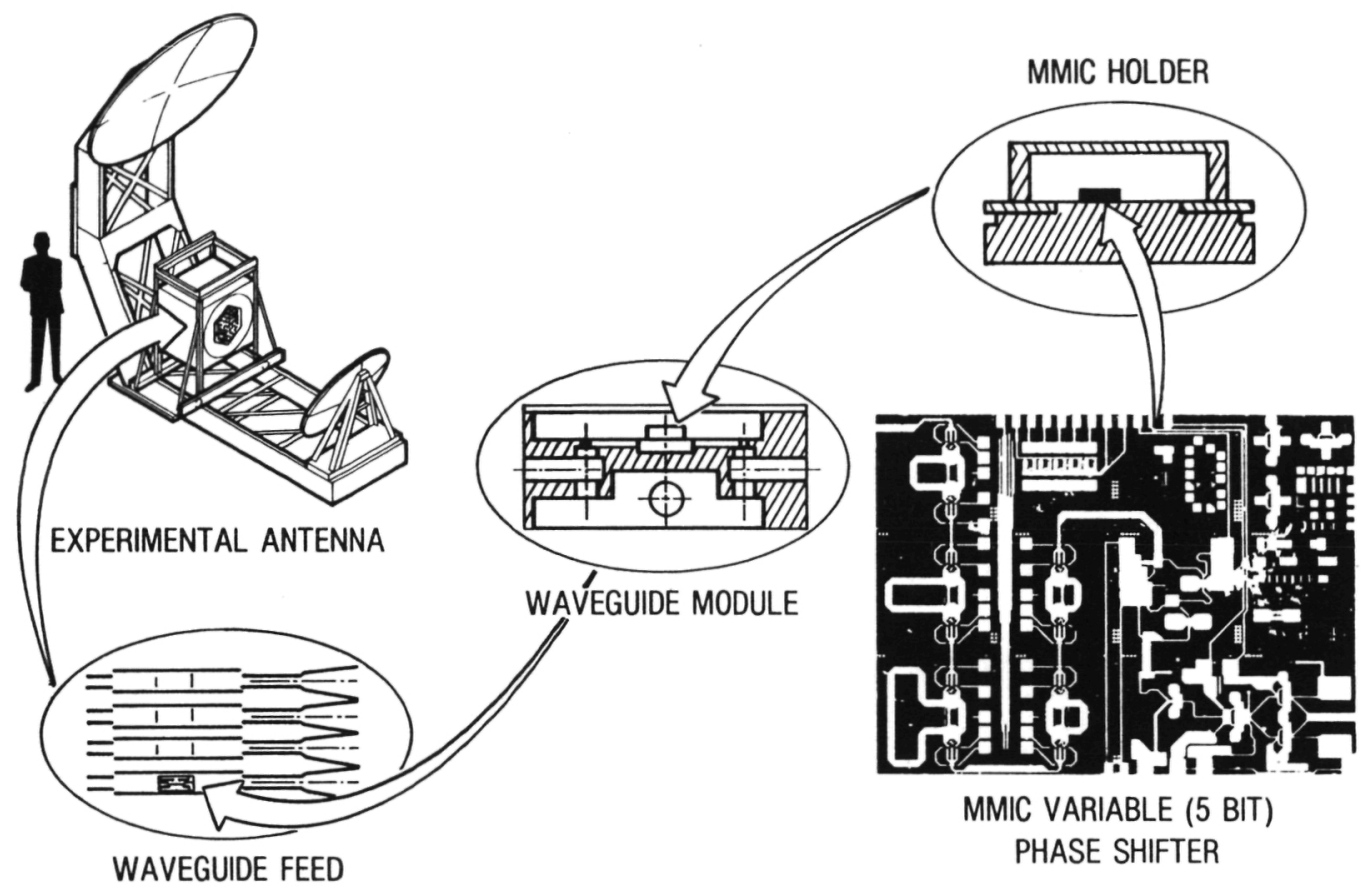

CD-85-18140

Figure 13. - Experimental antenna system design concept. 


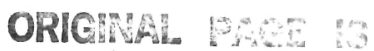

OF POOR QUALITY



Figure 14. - Two designs for $20 \mathrm{GHz} \mathrm{MMIC}$ holders for use in experimental antena system.

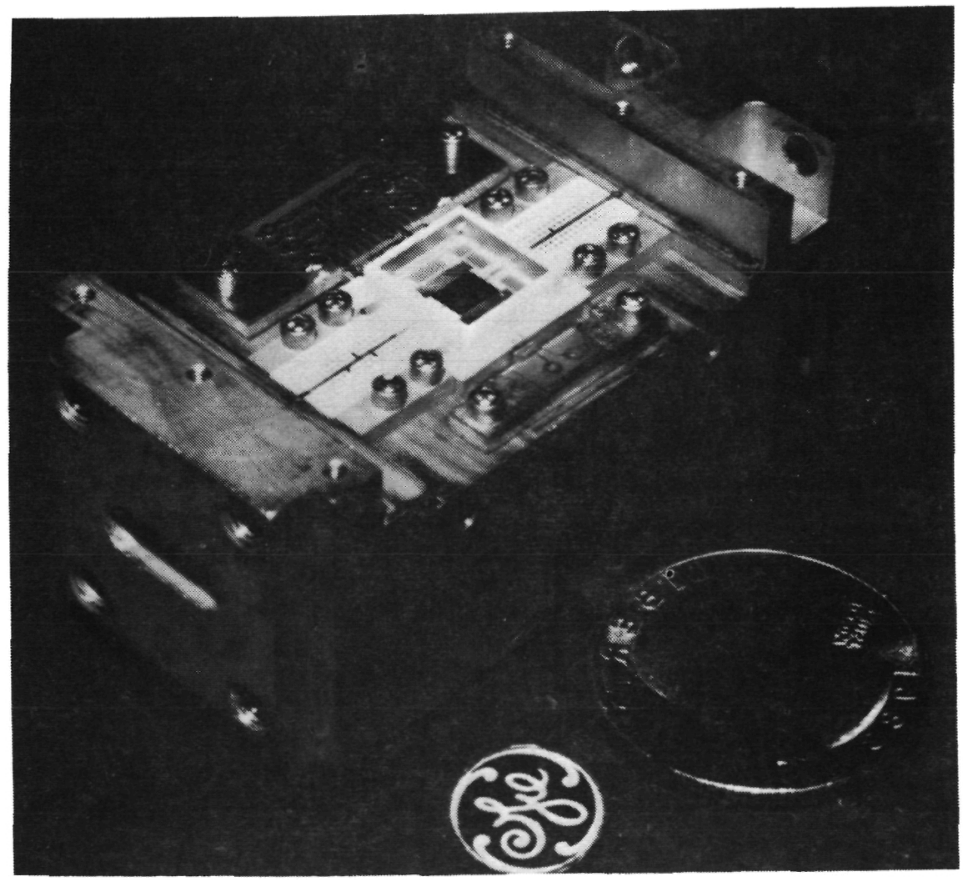

Figure 15. - $20 \mathrm{GHz}$ waveguide housing for EAS. 


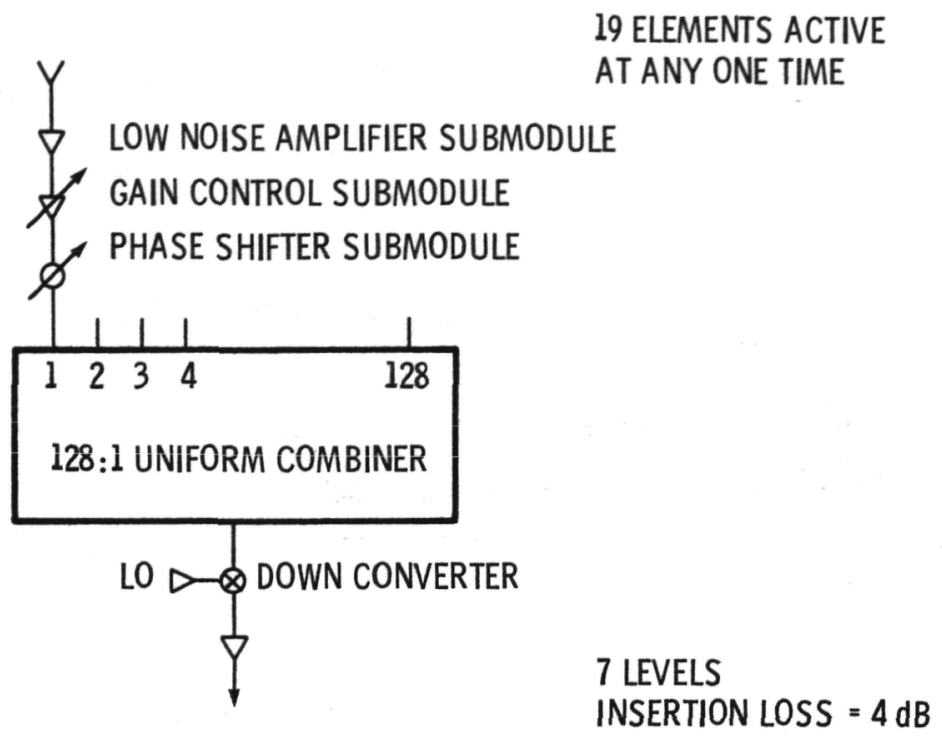

(a) Signal combiner for one scanning beam.

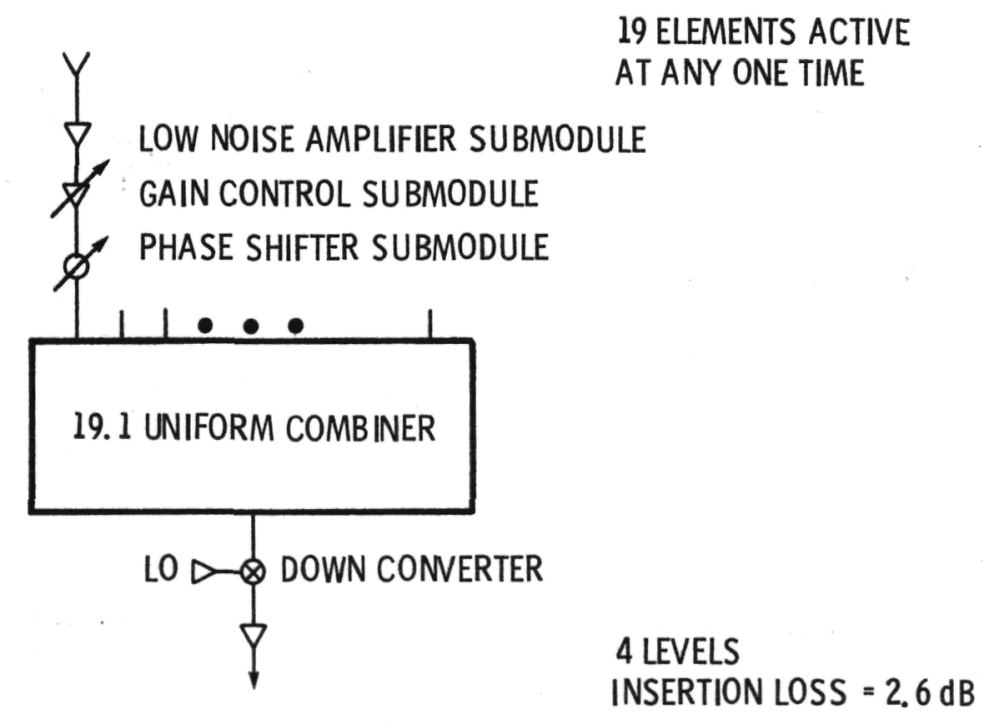

(b) Signal combiners for one fixed beam.

Figure 16. $-30 \mathrm{GHz}$ receive MMIC configurations. 


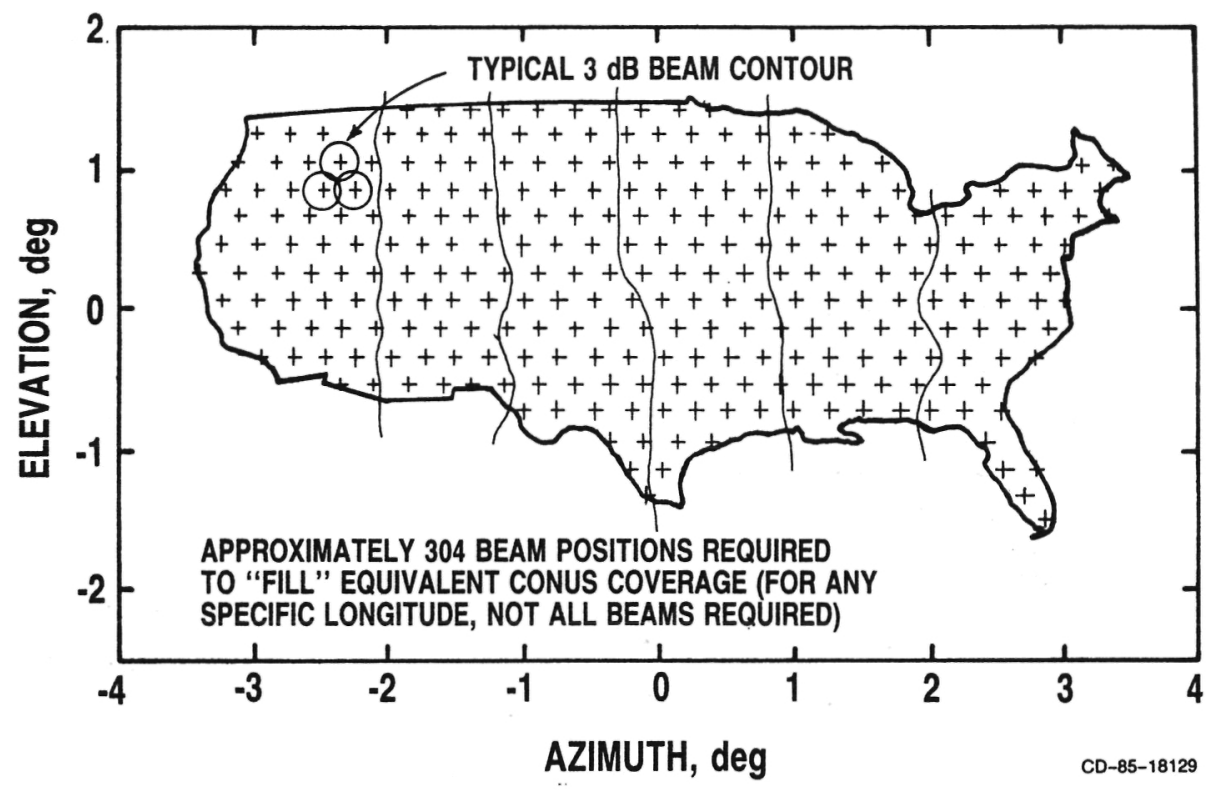

(a) Multiple scanning beam coverage concept.

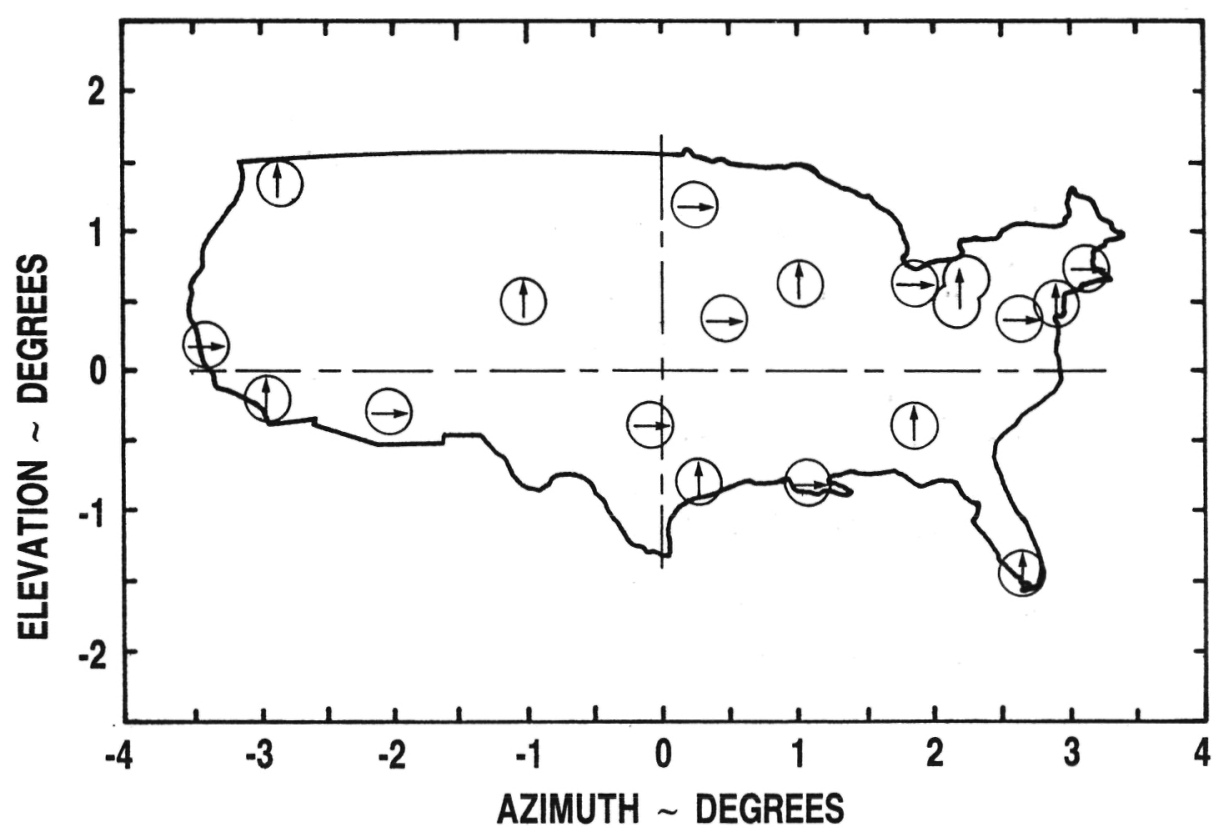

(b) Multiple fixed beam coverage concept.

Figure 17. - Multiple beam coverage concepts. 


\begin{tabular}{|c|c|c|c|}
\hline $\begin{array}{l}\text { 1. Report No. } \\
\text { NASA TM-87192 }\end{array}$ & 2. Government Accession No. & \multicolumn{2}{|c|}{ 3. Recipient's Catalog No. } \\
\hline \multicolumn{2}{|c|}{$\begin{array}{l}\text { 4. Titie and Subtitle } \\
\text { MMIC Antenna Technology Development in the } \\
30 / 20 \text { Gigahertz Band }\end{array}$} & \multicolumn{2}{|l|}{ 5. Report Date } \\
\hline \multirow{2}{*}{\multicolumn{2}{|c|}{$\begin{array}{l}\text { 7. Author(s) } \\
\text { J. Smetana, T.J. Kascak, and R.E. Alexovich }\end{array}$}} & \multicolumn{2}{|c|}{$\begin{array}{l}\text { 8. Performing Organization Report No. } \\
\text { E-2848 }\end{array}$} \\
\hline & & \multicolumn{2}{|l|}{ 10. Work Unit No. } \\
\hline \multicolumn{2}{|c|}{$\begin{array}{l}\text { 9. Performing Organization Name and Address } \\
\text { National Aeronautics and Space Administration } \\
\text { Lewis Research Center } \\
\text { Cleveland, Ohio } 44135\end{array}$} & \multicolumn{2}{|c|}{\begin{tabular}{|l|} 
11. Contract or Grant No. \\
13. Type of Report and Period Covered \\
Technical Memorandum
\end{tabular}} \\
\hline \multicolumn{2}{|c|}{$\begin{array}{l}\text { 12. Sponsoring Agency Name and Address } \\
\text { Nationa } 1 \text { Aeronautics and Space Administration } \\
\text { Washington, D.C. } 20546\end{array}$} & \multicolumn{2}{|c|}{ 14. Sponsoring Agency Code } \\
\hline \multicolumn{4}{|c|}{$\begin{array}{l}\text { 15. Supplementany Notes } \\
\text { Prepared for the } 11 \text { th Annual Communications Satellite Systems Conference, } \\
\text { sponsored by the American Institute of Aeronautics and Astronautics, San Diego, } \\
\text { California, March } 16-20,1986 \text {. }\end{array}$} \\
\hline \multicolumn{4}{|c|}{$\begin{array}{l}\text { 16. Abstract } \\
\text { This paper presents a progress summary of NASA's efforts in developing } 20 \text { and } 30 \\
\text { GHz GaAs MMIC devices and an advanced satellite communications antenna system } \\
\text { using these devices. In the interest of preserving resources such as frequency } \\
\text { spectrum and orbital space the antenna system is being developed with multiple } \\
\text { fixed spot beams and multiple scanning spot beams. NASA set high goals for the } \\
\text { MMIC development to push GaAs technology. These goals and the main features of } \\
\text { the MMIC devices are discussed. Some packaging and characterization considera- } \\
\text { tions are also discussed. The } 20 \text { GHz transmit antenna and } 30 \text { GHz receive antenna } \\
\text { are being developed separately. The approach selected is to perform contractual } \\
\text { configuration studies, purchase a } 20-\text { GHz experimental antenna system (EAS) and } \\
\text { perform in-house evaluation. The features and key specifications of the EAS are } \\
\text { discussed. Additional supporting technologies such as effects of coupling on } \\
\text { modest sized arrays, MMIC matching techniques, in-house analytical capability, } \\
\text { wideband and dual frequency microstrip patch array development, and MMIC packag- } \\
\text { ing techniques are described. Some plans for future are also discussed. }\end{array}$} \\
\hline $\begin{array}{l}\text { 17. Key Words (Suggested by Authorls } \\
\text { Antenna; Array; MM } \\
\text { Communications }\end{array}$ & $\begin{array}{r}\text { 18. Dis } \\
\text { Ur }\end{array}$ & $\begin{array}{l}\text { ent } \\
\text { ed }- \text { un } 17 \text { imit }\end{array}$ & \\
\hline $\begin{array}{l}\text { 19. Security Classif. (of this report) } \\
\text { Unc las s if ied }\end{array}$ & $\begin{array}{l}\text { 0. Security Classif. (of this page) } \\
\text { Unc lass if if }\end{array}$ & 21. No. of pages & 22. Price* \\
\hline
\end{tabular}

"For sale by the National Technical Information Service, Springfield, Virginia 22161 
National Aeronautics and

Space Administration

Lewis Research Center

Cleveland. Ohio 44135

Official Business

Penalty for Private Use $\$ 300$
SECOND CLASS MAIL

ADDRESS CORRECTION REQUESTED
Postage and Fees Paid

National Aeronautics and

Space Administration

NASA-451 